\title{
Malaysian Millennials' Clothing Apparel Choice: A Study on Brand Factors and the Implications on Consumer Preferences
}

\author{
Sunitha Mary a/p Viapulam \\ Reign Consultancy \& Management \\ E-mail: Sunitha@ reignmalaysia.com \\ Muhammad Farooq \\ Limkokwing University Malaysia \\ E-mail: Farooq.buzdar2@gmail.com
}

Received: February 7, 2019

Accepted: March 29, 2019

Published: March 31, 2019

doi:10.5296/ijim.v4i1.14632

URL: https://doi.org/10.5296/ijim.v4i1.14632

\begin{abstract}
The objective of this research is to examine the effects of brand factors and country of origin factors on self-concept and its implications on consumer preference. Furthermore, the research also studied the moderating effect of fashion consciousness on consumer preference. The research is centred on the Malaysian Millennials in the clothing industry. The data for this research is obtained through primary data survey that was conducted through physical questionnaire distribution and online questionnaires sent via Google Forms. A total number of 230 responses were collected and analysed using factor analysis and partial least squares structural equation modelling (PLS-SEM) techniques. The findings indicated that brands factors had greater impact on self-concept in comparison to country of origin. The brand association and brand personality dimensions were found to have significant roles in brand factors. Self-concept is found to have a positive influence on consumer preference. However, fashion consciousness did not moderate the relationship between self-concept and consumer preference. The findings of this study will be useful to marketers to devise a more strategic marketing mix and develop a suitable market entry strategy based on the contributing factor that would yield a better return on investment (ROI).
\end{abstract}

Keywords: Millennials, Brand choice, Brand association, Brand preferences, Malaysia 


\section{Introduction}

Consumers around the world are facing challenging situation during purchase decisions. Magnified globalization has resulted in the consumer market being flooded with variety of local and global brands. According to Nielsen Global Brand report, it was indicated that consumers in Malaysia as well as from other Asian regions show preference for global brands compared to locally manufactured goods (Hew 2017). The report highlighted that nine out of 10 consumers in Malaysia choose global brands especially for baby related products.

There have been numerous studies on western brand implication in specific countries such as in Vietnam, India and Singapore (Kumar et al., 2009). The studies highlighted how Asian consumers have desires for western products particularly in the minds of those who are brand conscious. It also postulated how western brands are associated with having an international look and consuming western brands is categorized as a 'passport to global citizenship' (Pham \& Richards, 2015). A research conducted on chocolate brand preference among the Malaysians found that Malaysian consumers were more familiar with western branded chocolates compared to locally manufactured brands. This is true not only for consumable products but also applicable for automobiles, education institutions, cosmetic products, apparels and others. In Malaysia, the preference for western brands could be due to higher brand awareness as well as a stable brand positioning in the global markets. Brands are not mere names of companies, but are perceived to provide consumers' meaning as well as to develop an image by communicating competencies, standards and personalities (Lim \& O’Cass, 2001).

This research will identify the significant factor that would influence self-concept which ultimately influences the Millennials' purchase preference. In particular objectives of the research are to determine: whether brand factors or COO or both have significant effect on self-concept; which dimension in brand factors has a significant effect on self-concept; which dimension in $\mathrm{COO}$ has a significant effect on self-concept; whether self-concept has an influence on consumer preference and; if fashion consciousness moderates the effect of self-concept on consumer preference.

\section{Literature Review}

Clothing is an essential part of an individual's life. On an average, clothing and footwear expenditure by Malaysians contribute to approximately 3.4 percent of the monthly household consumption expenditure. The younger generation particularly has been seen to significantly splurge on clothing and footwear products as they have acquired spending power (Radder \& Huang, 2008). "Moonlight Clan" a term used on Millennials in China to illustrate their spending patterns, reveals how the younger generation spend chunks of their salaries on branded items to express their unique personalities (Ren, 2018). Clothing is used as tools to develop self-identities and communicate these identities to others. Due to the greater occupancy of fashion clothing in a consumer's life, clothing apparels are perceived to possess a higher product involvement. As a consequence, clothing is categorized as a high involvement product as it is attested to evoke emotions and is of a hedonic nature (Kumar et al., 2009). 
Sasmita and Suki (2014) found that the younger generations are the highest contributors to branded products. Understanding the younger generation has become important as they have been predicted to have a significant effect on retail spending for years to come. Consumers begin their brand preference journey at a younger age which is from 15 to 25 years of age (Radder \& Huang, 2008). Amongst the various industries, the apparel industry is where branding is used extensively to differentiate and to gain a competitive advantage by marketers (Buzdar, Janjua, \& Khurshid, 2016; Farooq \& Jabbar, 2014; Farooq et al., 2018; Qadir \& Farooq, 2018)

\subsection{Brand Factors}

Brand is defined as an 'offering from a known source'. Brands are also defined as "complex multidimensional constructs with varying degrees of meaning, independence, co-creation and scope" (Brodie \& Benson-Rea, 2016). The long-term relationship consumers develop with brands is expounded by brand resonance model (Farooq, 2019; Irshad, Madeeha; Farooq, 2015; Tolulope, Folarin, \& Farooq, 2018). Brand resonance model examines the customer-brand relationship and identifies the extent the consumers' are synchronized with the brand. The model studies different dimensions of brands which includes brand awareness, brand image and its association with country image, brand association, brand perception, brand loyalty and more. For the purpose of this research, dimensions related to clothing apparels will be analyzed. Brand factors includes brand image, brand perception, brand personality and brand association

\subsection{Economic Aspects of Country-of- Origin}

Economic development of $\mathrm{COO}$ of a brand is important as it influences consumer's perception. Generally countries are acknowledged for specific excellence such as the French for expensive perfumes, Germans for electronic cars, the Swiss for watches and more. Economically developed countries enjoy a positive image or perception among consumers. Consumers in developed countries preferred local products however; consumers in developing countries were more inclined to imported products. Therefore, consumers perceive products from economically developed countries to have superior quality. Consumption of these global products is known to exhibit prestige, status and esteem which has an impact on self-concept. Hence, there exists a positive correlation between the economical factor of $\mathrm{COO}$ and product evaluation.

\section{$2.3 \mathrm{COO}$ and Self-Concept}

Khan and Rodrigo (2013) suggested that COO effects self-image and consequently influences purchase intentions towards foreign product. $\mathrm{COO}$ is said to act as a cognitive cue that provides a symbolic and emotional meaning to consumers that constructs social identity (Pham \& Richards, 2015). A research conducted in Sri Lanka introduced a term referred to as 'glocal elites'. Khan and Rodrigo (2013) defined the term 'glocal elites' as 'consumers with high social status, income and global mind-set'. The research postulated that there is a positive relationship between the $\mathrm{COO}$ of a product and self-image which has an impact on consumers' attitude towards foreign products (Khan \& Rodrigo, 2013). Hence it can be 
concluded that $\mathrm{COO}$ has a positive impact on self-concept

Fashion is defined as "a wave of social conformity" or "a style that is accepted by a large number of people at a given time" (Mandhachitara \& Paimphongsan 2011). Fashion consciousness is referred to consumers who are highly involved in fashion trends and constantly update their clothing line by shopping more often (Hassan \& Harun, 2016; Leung et al., 2015). Other studies have also found conscious individuals who are concern of their self-image and self-identity tend to rely on fashion particularly from western region to elevate their image (Hassan \& Harun, 2016).

Branded fashion items significantly reflect consumer's desire, and preference level. Rathnayake (2011) indicated that an individual's clothing preference is influenced by self-concept. Hence, fashion elements have been found to have a moderating effect on self-concept as the visibility of fashion usage is to achieve social recognition and approval by the segment of a society (Hassan \& Harun, 2016). Thus, fashion consciousness is found to moderate the relationship between self-concept and consumer preference.

\section{Conceptual Framework}

The conceptual framework was devised purely from past researches and literature review. There are three independent variables. The first independent variable is brand factors and its dimensions are brand image, brand perception, brand personality and brand association. The connection between brand factors and self-concept is developed based on Japutra et al. (2018). The second independent variable is country of origin and the dimensions are economic development, socio-cultural factors and technological factors. The last independent variable is self-concept. The relationship between the country of origin and self-concept is developed based on Khan and Rodrigo's (2013) framework. The moderating variable is fashion consciousness and the dependent variable is consumer preferences. The framework was developed based on identified variables that are relevant to the problem statement. The model displays causality relationship between the brand factors, country of origin with consumer's self-concept which has an influence on their consumer preferences.

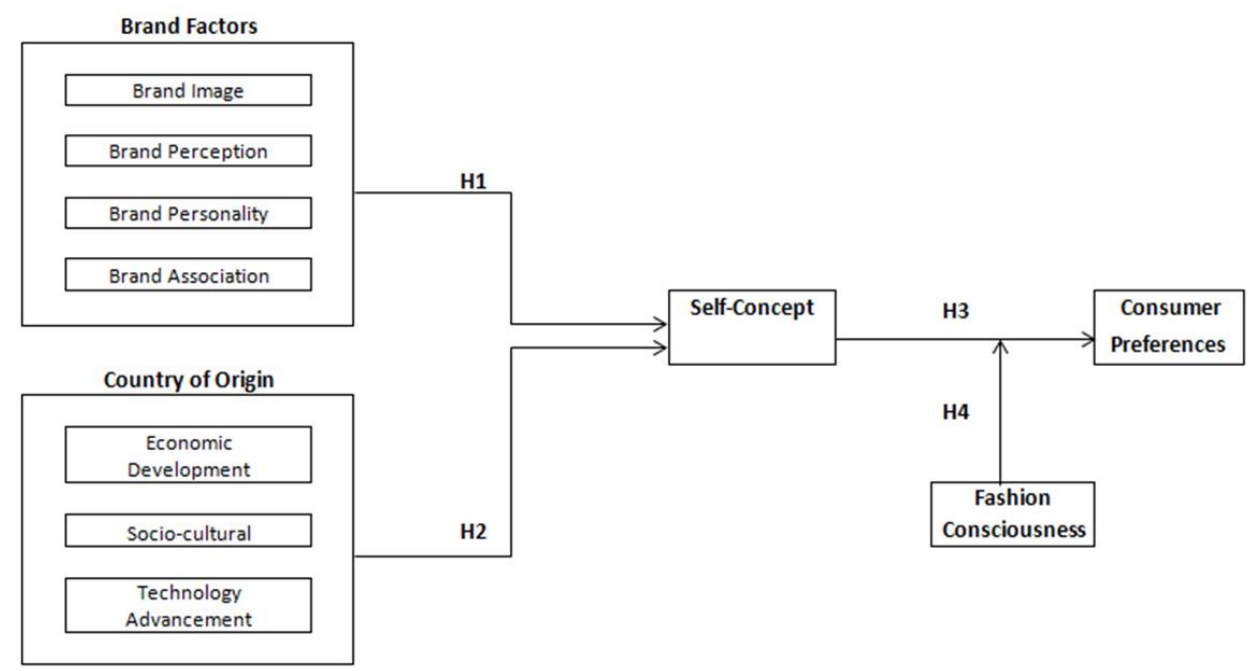

Figure 1. Proposed framework 


\subsection{Research Hypothesis}

Hypothesis is a statement that denotes the relationship between two or more variables of a study (Cohen et al., 2007). The hypothesis for this research is illustrated below.

Hypothesis 1: Brand factors have a positive influence on Self-concept

Hypothesis 2: Country of origin has a positive influence on Self-concept

Hypothesis 3: Self-concept is positively related to Consumer Preference

Hypothesis 4: Fashion consciousness moderates the relationship between Self-concept and Consumer Preference.

\section{Research Design}

A research design involves decision making selections required for a study. A research design involves acquiring data by using different combinations, analyses and methods to supplement limitations that may arise from other methods used. A research design is selected after much consideration in terms of time constraint and cost. According to the Department of Statistics of Malaysia, Klang Valley recorded the highest population number in 2016. Therefore, samples were obtained from the Klang Valley region for this study. Based on guidelines of Barlett et al. 2001 a sample size of 374 was required for the research.

The data for the research is obtained through various methods such as self-administered questionnaire and via online portal through Google Forms. Snowballing sampling technique is used to distribute the questionnaire. Snowballing technique is known as 'a process of reference from one person to the next'. It is an ideal method to acquire more respondents within a social circle. The data obtained is first-hand data that can be classified as primary source of data. The secondary data refers to theoretical models, literature reviews and other existing sources or information that is available. A combination of primary and secondary data was gathered for this study.

Survey was conducted to collect data for this research. The survey questionnaire was distributed manually as well as via Google forms. The online questionnaire was selected due to time constraint as well as it would have larger coverage from the snowballing effect. The self-administered questionnaire was also advantageous as it enabled the questionnaire to be given to the appropriate group and collected immediately upon completion.

The data for the purpose of this study is collected via online survey and self-administered survey over six weeks. The self-administered survey is carried out in various private colleges located in the Klang Valley region. The conceptual framework is measured using multiple item measurement scale to obtain a wider range of possible scales. For the purpose of this research, a five point Likert-type scale was used ranging from Strongly disagree to Strongly agree for sections two until section six in the questionnaire.

\section{Analysis and Results}

Statistical Packages for Social Sciences (SPSS), Version 22.0 and Smart PLS version 3.0 for 
Partial Least Square - Structural Equation Modelling (PLS-SEM) was utilized to analyze the data obtained from the survey conducted. The demographic profile of the respondents was analyzed by using SPSS. The PLS-SEM modeling was utilized for inner and outer model evaluation.

\subsection{Demographic and Descriptive of the Study}

Male respondents represented only 34.3 percent of the entire sample whereas the female respondents represent 65.7 percent of the sample. The female respondents are much higher and therefore the gender is not equally distributed for this study. The highest respondent for this sample represents respondents who are 18 to 22 years of age which is 53.9 percent. The second highest is 38.3 percent which represents respondents who are between 23 and 27 years of age. The remaining 7.8 percent of the respondents are 28 years and above. The entire population constitutes the younger population who are below 35 years of age. The three main ethnic groups in Malaysia are Malay, Chinese and Indian is represented. The majority of the respondents are Indians which represents 42.6 percent and this is followed by the Chinese which is 34.8 percent. The average percentage for the three main ethnic groups is almost equally distributed that is 31.9 percent. The highest respondents are found to be diploma holders that represent 47.4 percent. The lowest respondents are those with doctorate degree which represents only 1.7 percent of the entire sample. Others in the education level are respondents with certificates and A-level qualification. Respondents with an income level below RM 1,000 that represents 41.7 percent are the largest group in the sample. The possible reasoning for a lower income level could be due to the fact that the majority of the respondents are students who get an allowance. Approximately 26.1 percent of the respondents fall under the RM2,000 income level. Respondents who have income above RM 2,500 were 22.6 percent of the entire sample.

The majority of the respondents are inclined towards western brands which is 69.6 percent of the entire sample. Only 5.6 percent purchase Malaysian brand labels. Respondent who purchase both western and local brands represent 24.8 percent.

The amount spent by respondents on clothing apparels in the last six months. Majority of the respondents spend approximately RM 100 to RM 300 on clothing apparels. Around 33.9 percent of the respondents spend less than RM 100 for clothing. Only 6.1 percent of the respondents spend above RM 1,000 for clothing apparels in the last six months.

A percentage of 61.4 percent of the sample population purchase clothing apparels two to three times in a year. This is followed by 24.7 percent of the respondents who purchase clothing apparels four to six times in a year. The remaining respondents that are 13.9 percent purchase more than seven times in a year.

\subsection{Reliability and Validity}

Reliability of the reflective outer models should be tested for reliability and validity. The most commonly used reliability test by academician is Cronbach's Alpha which is a generalized measure for uni-dimensional and multi-item scale's internal consistency. A high alpha value indicates that the scores of all items in one construct share the same range. 


\section{Macrothink}

However, the disadvantage of the Cronbach alpha is that it assumes that all indicators are equally reliable (Hair et al., 2014). Composite reliability (CR) is a better option as it accommodates different indicator reliability (Hair et al., 2014). The accepted internal consistency values are above .700 for both the Cronbach alpha and CR. A higher CR value indicates internal consistency and the measures represent the same construct. The lowest CR value was recorded for fashion consciousness.

\subsubsection{Reliability Results}

Table 1 . Reliability results

\begin{tabular}{lcc}
\hline & Cronbach's Alpha & Composite Reliability \\
\hline Brand Factors & 0.933 & 0.943 \\
Country of Origin & 0.929 & 0.938 \\
Self-concept & 0.871 & 0.913 \\
Fashion Consciousness & 0.807 & 0.868 \\
Consumer Preference & 0.887 & 0.912 \\
\hline
\end{tabular}

\subsubsection{Convergent Validity}

Convergent validity assess the degree to which individual reflective items converges in comparison to items measuring different constructs. Average Variance Extracted (AVE) is performed to assess the validity and the summary of the results.

Table 2. Convergent validity assessment

\begin{tabular}{lccc} 
& $\begin{array}{c}\text { Cronbach's } \\
\text { Alpha }\end{array}$ & $\begin{array}{c}\text { Composite } \\
\text { Reliability }\end{array}$ & $\begin{array}{c}\text { Average } \\
\text { Variance } \\
\text { Extracted } \\
\text { (AVE) }\end{array}$ \\
\hline Brand Factors & 0.933 & 0.943 & 0.564 \\
Country of Origin & 0.929 & 0.938 & 0.521 \\
Self-concept & 0.871 & 0.913 & 0.726 \\
Fashion Consciousness & 0.807 & 0.868 & 0.623 \\
Consumer Preference & 0.887 & 0.912 & 0.599
\end{tabular}

The AVE represents the grand mean value of the squared loadings of indicators (Hair et al., 2014). The convergent validity is supported or is sufficient when the AVE value is 0.5 or higher. The AVE values for this research are within the accepted range which is within 0.50 and 0.75 . Therefore, all the constructs demonstrate sufficient convergent validity.

\subsubsection{Discriminant Validity}

Fornell-Larcker criterion (1981) was utilized to measure degree to which the measures of 
different constructs differ from one another. A high discriminant validity indicates uniqueness of the constructs (Hair et al., 2014).

Table 3. Discriminant validity using Fornell-Larcker's Criterion

\begin{tabular}{|l|r|r|r|r|r|}
\hline & Brand Factors & $\begin{array}{c}\text { Country of } \\
\text { Origin }\end{array}$ & Self-concept & $\begin{array}{c}\text { Fashion } \\
\text { Consciousness }\end{array}$ & $\begin{array}{c}\text { Consumer } \\
\text { Preference }\end{array}$ \\
\hline Brand Factors & $\mathbf{0 . 7 5 1}$ & & & & \\
Country of Origin & 0.815 & $\mathbf{0 . 7 2 2}$ & & & \\
Self-concept & 0.818 & 0.738 & $\mathbf{0 . 8 5 2}$ & & \\
Fashion Consciousness & 0.471 & 0.541 & 0.470 & $\mathbf{0 . 7 8 9}$ & \\
Consumer Preference & 0.738 & 0.727 & 0.734 & 0.579 & $\mathbf{0 . 7 7 4}$ \\
\hline
\end{tabular}

Table 3 depicts the discriminant validity for the constructs and it is found that brand factors and country of origin have discriminant validity issues. There are disadvantages of using the traditional Fornell-Larcker criterion when additional constructs are added to a model. In instances where an extended model is studied, Henseler et al. (2015) proposed the use of the Heterotrait-Monotrait Ratio (HTMT) which would be suitable to assess the correlations among items of the reflective measured constructs (Hair et al., 2017). Any value above 0.90 indicates a lack of discriminant value (Hair et al., 2017, p. 119).

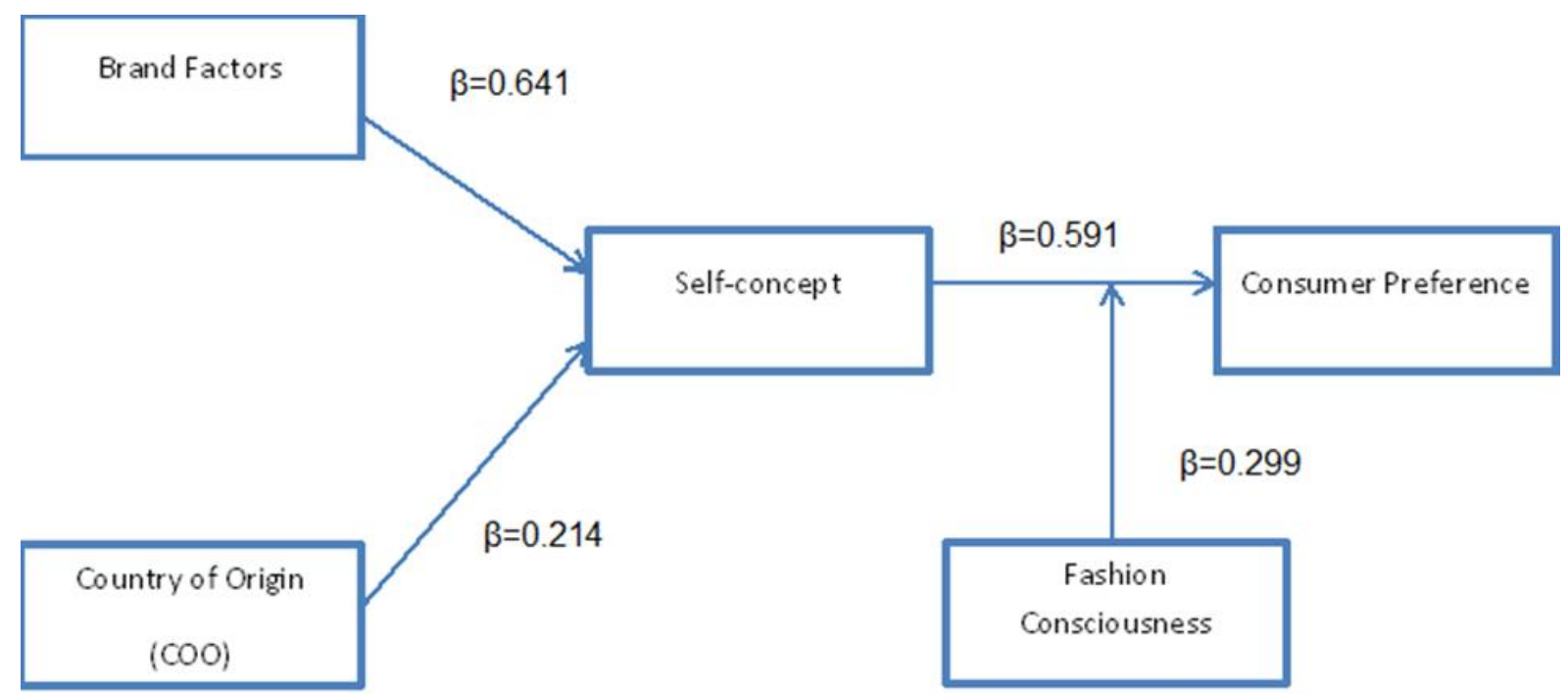

The p-value is below 0.01 and thus indicates that all loadings are significant. 


\section{Macrothink}

Table 4. Path Coefficient with p-value

\begin{tabular}{lccc}
\multicolumn{1}{c}{ Constructs } & Standard $\beta$ & t-value & p-value \\
& & & \\
Brand Factors $\rightarrow$ Self-concept & 0.641 & 8.781 & 0.000 \\
Country of Origin $\rightarrow$ Self-concept & 0.214 & 2.792 & 0.005 \\
Self-concept $>$ Consumer Preference & 0.591 & 12.080 & 0.000 \\
Fashion Consciousness $\rightarrow$ Consumer Preference & 0.299 & 6.117 & 0.000
\end{tabular}

Brand factors effect on self-concept is significant with a positive path coefficient of 0.641 which is significant at a $\mathrm{p}$-value of $0.000(\beta=0.641, \mathrm{p}<0.01)$. Country of origin also demonstrates a positive path coefficient of 0.214 and a $p$-value of $0.005(\beta=0.214, p<0.01)$. This is followed by the path coefficient of self-concept which recorded a positive value of 0.591 and a $p$-value of $0.000(\beta=0.591, p<0.01)$. The moderating factor fashion consciousness also indicated a positive path coefficient value of 0.299 with a $p$-value of $0.000(\beta=0.298$, $\mathrm{p}<0.01)$.

\subsection{Assessment of Coefficient of Determination $\left(R^{2}\right)$}

The coefficient of determination measures the relationships between the exogenous variable's combined effect on the endogenous variable (Hair et al., 2014). According to Chin (1998) $\mathrm{R}^{2}$ values with .670 are considered substantial, values approximately .333 are ranked as average and values of .190 and lower are described as weak. The $\mathrm{R}^{2}$ values for both self-concept and consumer preference has substantial values.

Table 5. Coefficient of determination $\mathrm{R}^{2}$ - self-concept and consumer preference

\begin{tabular}{lc}
\hline & $\mathbf{R}^{2}$ \\
\hline Self-concept & 0.684 \\
Consumer Preference & 0.609 \\
\hline
\end{tabular}

\subsection{Assessment of Effect Size, ( $f 2$ )}

Cohen's $\mathrm{f}^{2}$ measures the effect of the independent variable has on the dependent variable (Hair et al., 2014). It provides additional insights about the quality between the variables. According to Cohen's $\mathrm{f}^{2}$ guidelines, values of $0.02,0.15$ and 0.35 respectively represents small, medium and large effects (Hair et al., 2017). The value of effect size $\mathrm{f}^{2}$ for this study ranged from 0.048 to 0.705 .

Table 6 . The Effect size $\mathrm{f}^{2}$ of the variables

\begin{tabular}{lcc}
\multicolumn{1}{c}{ Constructs } & F2 & Inference \\
\hline Brand Factors to Self-concept & 0.439 & Brand factors have large effect on Self-concept \\
Country of Origin to Self-concept & 0.048 & Country of origin has medium effect on Self-concept \\
Self-concept to Consumer Preference & 0.705 & Self-concept has a large effect on Consumer preference \\
Fashion Consciousness to Consumer Preference & 0.175 & Fashion consciousness has medium effect on Consumer preference
\end{tabular}




\section{Macrothink}

Between the two independent variable of the study, brand factors have larger effect on self-concept with a value of 0.439 compared to country of origin which only recorded a value of 0.048. The largest effect was derived from self-concept and consumer preference with a value of 0.705 . Fashion consciousness indicated a medium effect on consumer preference.

\subsection{Moderating Relationship in PLS Model}

The primary objective of the moderator is to establish a link that shows a significant interaction with the constructs. When the value of the interaction is significant, then it is safe to conclude the relationship (Hair et al., 2017). The first step in testing for moderating effect, a 'dummy construct' is created and self-concept is selected as the independent variable and consumer preference as the dependent variable. The dummy variable in the image is represented in green. Bootstrapping procedure facilitates this assessment. Based on the p-value obtained which is higher than the 0.05 threshold, it was found that fashion consciousness does not moderate between self-concept and consumer preference.

\section{Moderating Relationship - Fashion Consciousness}

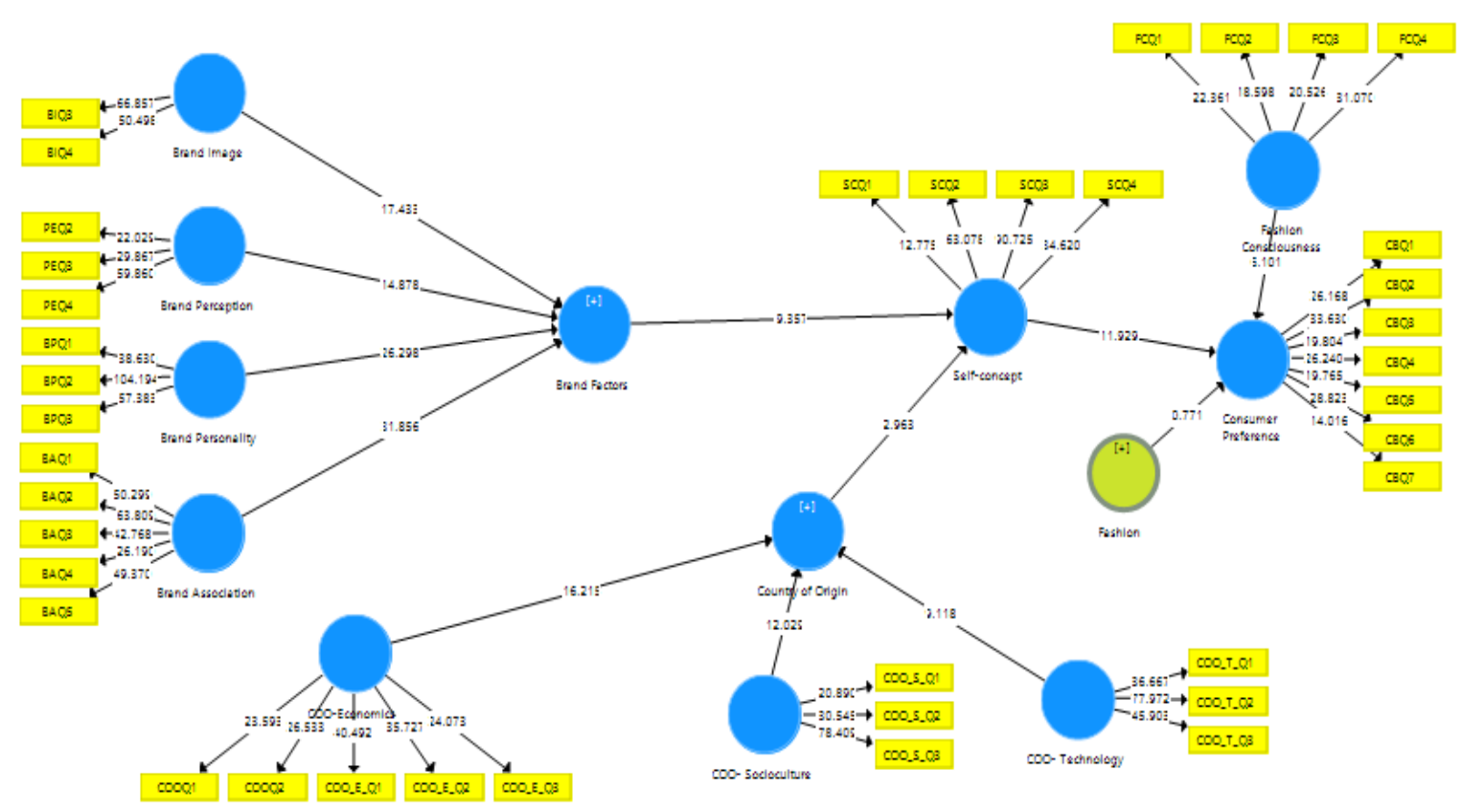

Table 7. Test results for moderating relationship

\begin{tabular}{clcccc} 
Hypothesis & Relationship & Standard $\beta$ & t-value & p-value & Decision \\
\hline H4 & $\begin{array}{l}\text { Fashion Consciousness } \rightarrow \text { Consumer } \\
\text { Preference }\end{array}$ & 0.041 & 0.792 & 0.429 & $\begin{array}{c}\text { Not } \\
\text { Supported }\end{array}$
\end{tabular}

\section{Discussions and Conclusions}

Based on the outcomes, it was found that brand factors have a greater effect on self-concept 


\section{Macrothink}

in comparison to country of origin. Though country of origin has a positive effect on self-concept, it was not substantial. Self-concept has a positive effect on consumer preference. In contrary to the proposed hypothesis, fashion consciousness did not moderate the relationship between self-concept and consumer preference.

The first research objective is to evaluate if brand factors have a positive influence on self-concept and is addressed by hypothesis H1. The second hypothesis developed evaluates the effect of country of origin on self-concept and is represented by $\mathrm{H} 2$. The fourth objective of the research aims to evaluate the positive relationship of self-concept on consumer preference and is addressed in hypothesis H3. The final proposed hypothesis H4 is to identify if fashion consciousness moderates the relationship between self-concept and consumer preference. Based on the empirical findings, hypotheses $\mathrm{H} 1, \mathrm{H} 2$ and $\mathrm{H} 3$ are supported whereas $\mathrm{H} 4$ is not supported.

Table 8. Research objectives, hypotheses and results

\begin{tabular}{|c|c|c|}
\hline \multicolumn{3}{|c|}{ To determine whether brand factors or $\mathrm{COO}$ or both have significant effect on self-concept. } \\
\hline & Brand factors have a positive influence on self-concept & Yes \\
\hline \multicolumn{3}{|c|}{ To determine whether brand factors or COO or both have significant effect on self-concept. } \\
\hline & Country of origin has a positive influence on self-concept & Yes \\
\hline \multicolumn{3}{|c|}{ To determine whether self-concept has an influence on consumer preference. } \\
\hline & Self-concept is positively related to consumer preference & Yes \\
\hline \multicolumn{3}{|c|}{ To determine if fashion consciousness moderates the effect of self-concept on consumer preference. } \\
\hline $\mathrm{H} 4$ & $\begin{array}{l}\text { Fashion consciousness moderates the relationship between self-concept and } \\
\text { consumer preference }\end{array}$ & \\
\hline
\end{tabular}

\subsection{Discussion of Findings}

The Millennials are found to fulfill their inner desire for self-expression through the consumption of symbolic brands. Hence, this young cohort is more inclined towards western brand clothing apparels to portray a positive self-image of them.

The brand factors consist of many dimensions such as brand image, brand association, brand personality and brand perception which were adopted from various scholars' such as Keller's brand resonance model (2010) and Aaker's brand model (1991). Brand factors in association with fashion apparels are important as these factors are rich in symbolic meaning and are used to express self-identity. 
Table 9. Brand Factors' Dimension

\begin{tabular}{lcccc}
\hline & $\begin{array}{c}\text { Cronbach's } \\
\text { Alpha }\end{array}$ & $\begin{array}{c}\text { Composite } \\
\text { Reliability }\end{array}$ & $\begin{array}{c}\text { Path } \\
\text { Coefficient }\end{array}$ & P- Value \\
\hline Brand Factors & & & & \\
Brand Association & 0.912 & 0.934 & 0.427 & 0.000 \\
Brand Personality & 0.884 & 0.929 & 0.169 & 0.004 \\
Brand Image & 0.798 & 0.908 & 0.079 & 0.119 \\
Brand Perception & 0.775 & 0.867 & 0.110 & 0.072 \\
\hline
\end{tabular}

Based on the findings, it was found that brand association is the main contributor for brand factors with a path coefficient of 0.427 and a satisfactory p-value of 0.00 . The second contributor is brand personality which also illustrates a strong relationship with a path coefficient value of 0.169 and a favorable p-value of 0.004 .

The COO factors are becoming complicated with increase in globalization where products are designed in one country, manufactured and sometimes assembled in another (Lim \& O'Cass, 2001). Hence, COO is not suitable to evaluate the quality and performance of a product and consequently explains the weak relationship between $\mathrm{COO}$ and self-concept.

According to the theories discussed in chapter 2, there exists a strong relationship between self-concept and consumer preference especially in the clothing apparel industry since clothing acts as a medium to communicate an individual's unique identity (Kumar et al., 2009). Therefore, marketers need to consider and understand factors that would elevate consumers' self-concept in order to capture the target market.

Though many researches have indicated a preference towards western brand clothing apparels, it is not the same for multi-ethnic consumer base such as Malaysia, where the majority of the population consists of Muslims. Therefore, not all products created by the western culture are appealing and congruent for Muslim consumers.

\subsection{Contributions of the Study}

The study conducted provides an insight on the effect of brand factors and COO factors on consumer preference among the Malaysian Millennials in the clothing apparel industry. Majority of the research conducted were based on one individual factor which is either brand related or COO. There were limited studies conducted simultaneously to identify the significant factor that influences consumer preference especially in the clothing apparel industry in Malaysia.

Based on the findings, marketers should emphasize more on brand factors particularly brand personality and brand association rather than promoting $\mathrm{COO}$ of a product line.

\subsection{Conclusion}

The objective of this research was to evaluate the brand factors and COO factors on self-concept and its implication on consumer preference. The objective was achieved through 
survey that was conducted on the Malaysian Millennials particularly in the clothing apparel segment. The proposed framework was developed from various studies conducted in the past. Based on the four proposed hypotheses, three hypotheses indicated positive relationships while one was not supported by the findings.

As acknowledged in literature review, brand factors play an important role in developing a positive self-concept of a consumer. This influence eventually affects the decision-making process and the consumption preference of individuals. Though COO plays a small role on product evaluation, however as suggested by Cordell (1992) it becomes irrelevant once a brand name is established (Parkvithee \& Miranda, 2012; Singh \& Mittal, 2017).

\section{References}

Brodie, R. J., \& Benson-Rea, M. (2016). Country of Origin Branding: An Integrative Perspective. The Journal of Product and Brand Management, 25(4), 322-336. https://doi.org/10.1108/JPBM-04-2016-1138

Buzdar, M. F., Janjua, S. Y., \& Khurshid, M. A. (2016). Customer-based brand equity and firms' performance in the telecom industry. International Journal of Services and Operations Management, 25(3). https://doi.org/10.1504/IJSOM.2016.079516

Cho, E., \& Fiore, A. M. (2015). Conceptualization of a Holistic Brand Image Measure for Fashion-Related Brands. The Journal of Consumer Marketing, 32(4), 255-265. https://doi.org/10.1108/JCM-07-2014-1063

Cohen, J. (1988). Statistical Power Analysis For The Behavioral Sciences (2nd ed.). Hillsdale, N.J.: L. Erlbaum Associates.

Farooq, M. (2019). Customer Experience Management: A Handbook to Acquire and Retain Valuable Customers. Cyberjaya: Kindle Direct Publishing (KDP). Retrieved from https://www.amazon.com/gp/product/B07MC8SJ4X/ref=dbs_a_def_rwt_bibl_vppi_i0

Farooq, M., \& Jabbar, Z. (2014). Role of Word of Mouth in building CBBE. Elixir Marketing Mgmt, 73, 26443-26447. Retrieved from http://www.elixirpublishers.com/articles/1408768877_73 (2014) 26443-26447.pdf

Hair, J., Sarstedt, M., Hopkins, L., \& Kuppelwieser, V. (2014). Partial Least Squares Structural Equation Modeling (PLS-SEM). European Business Review, 26(2), 106-121. https://doi.org/10.1108/EBR-10-2013-0128

Hew, V. (2017). Global or Local: What Do Malaysian Consumers Prefer?

Irshad, M., \& Farooq, M. (2015). Effect of Brand Tribalism on Customer Loyalty. Jurnal GMP Review of Marketing. Retrieved from https://www.researchgate.net/publication/285322441

Isa, A. (2014). Local Retailers Losing Out to Global Brands. The Edge Malaysia. Retrieved from

https://www.theedgemarkets.com/article/cover-story-local-retailers-losing-out-global-brands 
Japutra, A., Ekinci, Y., Simkin, L., \& Nguyen, B. (2018). The Role of Ideal self-congruence and Brand Attachement in Consumers' Negative Behaviour: Compulsive Buying and External Trash-talking. European Journal of Marketing, 52(3/4), 683-701. https://doi.org/10.1108/EJM-06-2016-0318

Khan, H., \& Rodrigo, P. (2013). Utilizing Product-Country-Image (PCI) -Self-image Congruity Intelligence to Target Glocal Elites in an Emerging Market: SMEs Perspective. In Proceeding of ICSB World Conference (pp. 1-14). International Council for Small Business (ICSB).

Kotler, P., \& Keller, K. (2016). Marketing Management. England: Pearson Education Limited.

Kumar, A., Youn-Kyung, K., \& Pelton, L. (2009). Indian Consumers' Purchase Behavior Toward US Versus Local Brands. International Journal of Retail \& Distribution Management, 37(6), 510-526. https://doi.org/10.1108/09590550910956241

Leung, C. Y., Yee, W. Y., \& Lo, S. C. (2015). Psychological and Social Factors of Fashion Consciousness: An Empirical Study in the Luxury Fashion Market. Research Journal of Textile and Apparel, 19(3), 58-69. https://doi.org/10.1108/RJTA-19-03-2015-B008

Levy, S., \& Hino, H. (2016). Emotional Brand Attachment: A Factor in Customer-bank Relationships. The International Journal of Bank Marketing, 34(2), 136-150. https://doi.org/10.1108/IJBM-06-2015-0092

Lim, K., \& O'Cass, A. (2001). Consumer Brand Classifications: An Assessment of Culture-of-origin Versus Country-of-origin. The Journal of Product and Brand Management, 10(2), 120-136. https://doi.org/10.1108/10610420110388672

Parkvithee, N., \& Miranda, M. J. (2012). The Interaction Effect of Country-of-origin, Brand Equity and Purchase Involvement on Consumer Purchase Intentions of Clothing Labels. Asia Pacific Journal of Marketing and Logistics, 24(1), 7-22. https://doi.org/10.1108/13555851211192678

Pham, H. C., \& Richards, B. (2015). The Western Brands in the Minds of Vietnamese Consumers. The Journal of Consumer Marketing, 32(5), 367-375. https://doi.org/10.1108/JCM-09-2014-1159

Qadir, A., \& Farooq, M. (2018). Impact of Evaluation Apprehension on Knowledge Sharing Intention through Attitude and Perceived Behavioural Control. International Journal of Academic Research in Business and Social Sciences, 8(6), 795-811. https://doi.org/10.6007/IJARBSS/v8-i6/4274

Radder, L., \& Huang, W. (2008). High-involvement and Low-involvement Products. Journal of Fashion Marketing and Management, 12(2), 232-243. https://doi.org/10.1108/13612020810874908

Ren, D. (2018). Chinese Millennials Give Luxury Brands a Boost as They Earn and Spend it All. South China Morning Post. 


\section{Macrothink}

International Journal of Industrial Marketing ISSN 2162-3066 2019, Vol. 4, No. 1

Sasmita, J., \& Mohd Suki, N. (2015). Young Consumers' Insights on Brand Equity. International Journal of Retail \& Distribution Management, 43(3), 276-292. https://doi.org/10.1108/IJRDM-02-2014-0024

Singh, A., \& Mittal, A. (2017). Assessing the Relationship between Country-of-Origin Image, Brand Image and Product Involvement with a Focus on Indian Consumers. International Journal of Applied Business and Economic Research, 15, 22.

Tolulope, B., Folarin, O., \& Farooq, M. (2018). Entrepreneurial Approach to Success: A Study of Warren Buffet of Mexico Carlos Slim.

\section{Copyright Disclaimer}

Copyright for this article is retained by the author(s), with first publication rights granted to the journal.

This is an open-access article distributed under the terms and conditions of the Creative Commons Attribution license (http://creativecommons.org/licenses/by/3.0/). 